der Informationen in Höchstgeschwindigkeit vollendet. Die Saure Phosphatase ist beim ganz jungen Tier bereits deutlich aktiv wie die Phosphoproteid-Phosphatase, zeigt sich aber stärker konzentriert in Hirnteilen, die reich an Leitungsbahnen sind, worin sie dem Kathepsin folgt. Die hier erfaßte phosphatabspaltende Aktivität - geprüft an einer körperfremden Phosphatverbindung - ist nicbt die mit anderer Methodik nachgewiesene Aktivität der Phosphoproteid-Phosphatase, sondern zeigt ein eigenes, charakteristisches Verhalten von Lokalisation und Aktivitätsverlauf.

Aus dem unterschiedlichen Verhalten der im Hirncytoplasma enthaltenen Aktivitäten von Kathepsin, Phosphoproteid-Phosphatase und Saurer Phosphatase schließen wir, daß es sich um drei wohlunterschiedene, voneinander unabhängige Fermente handelt. Untersuchungen $z u$ ihrer Isolierung und Charakterisierung sind im Gange.

\title{
Literatur
}

1. Ruchter, D., Brit. Med. J., 1255 (1959). - 2. WAELSCH, H., in: Metabolism of the nervous system, Hrsg. D. Richter Pergamon Press, London (1957). - 3. MÉrer, F. T. und F. Gallyas, J. Neurochem. 11, 257 (1964). - 4. POPE, A., J. Neurochem. 4, 32 (1959). - 5. Siebert, G., A. Schmitr und R. von Malortie, Hoppe-Seyler's Z. physiol. Chem. 342, 20 (1965). - 6. Haurowirz, F., Ann. New York Acad. Sci. 68, 3 (1957). - 7. Sundararajan, T. A. und P. S. SARMA, Biochem. J. 56, 125 (1954). - 8. AlBerT, E., Hoppe-Scyler's Z. physiol. Chem. 302, 129 (1955). - 9. Rodnighr, R., in: Protides of the Biological Fluids, Hrsg. H. Peeters, S. 39. Elsevier Publ., Amsterdam (1966). - 10. Rabinowitz, M. und F. LipManN, J. biol. Chemistry 235, 1043 (1960). 11. Heald, P. J., Phosphorus Metabolism in Brain. Pergamon Press, Oxford (1960). - 12. Rose, S. P. R., Biochem. J. 83, 614 (1962). - 13. Rose, S. P. R. und P. J. Heald, Biochem. J. 81, 339 (1961). - 14. WILLSTÄtTER, R. und E. BaMANN, Hoppe-Seyler's Z. physiolog. Chem. 180, 127 (1929). - 15. KIES, M. W. und S.
Schwimmer, J. biol. Chemistry 145, 685 (1942). - 16. Ansell, G. B. und D. Richrer, Biochim. biophysica Acta (Amsterdam) 13, 87 (1954). - 17. Palladin, A. V., N. M. Polyakova und V. K. Lrshko, J. Neurochem. 10, 187 (1963). - 18. Guropr, G., J. biol. Chemistry 239, 149 (1964). - 19. Huggins, C. und P. TALALAY, J. biol. Chemistry 159, 399 (1945). - 20. Duspiva, F., Protoplasma 32, 211 (1939). - 21. Lowry, O. H., N. J. Rosebrough, A. L. FarR und R. J. Randall, J. biol. Chemistry 193, 265 (1951). 22. Mrchaelis, L., Biochem. Z. 234, 139 (1931); Docum. Geigy, Wiss. Tab., 6. Aufl., S. 277 Basel (1960). - 23. Kutrner, Th. und L. Lichtenstein, J. biol. Chemistry 86, 671 (1930). - 24. La JTHA, A., in: Regional Biochemistry, Hrsg. S. S. Kety und J. Elkes, Pergamon Press, Oxford (1961). - 25. Polyakova, N. M., Y. V. BeLrK und L. A. SARYuK, Ukr. Biokhim. Zh. 32, 623 (1960). zit nach 17. - 26. Benufax, H., A. M. Berleur und A. Doyen, Biochem. J. 66, 32 (1957).

\section{Enzymatische Hydrolyse von Diäthyl-p-nitrophenylphosphat (E 600) durch menschliches Serum}

\author{
Von K. KrrsCH \\ Aus dem Pbysiologisch-Cbemischen Institut der Justus Liebig-Universität Gießen (Direktor: Prof. Dr. Hj. Staudinger)
}

(Eingegangen am 14. Juni 1967)

Es wird ein einfacher, kontinuierlicher photometrischer Test zur Messung der enzymatischen Hydrolyse von E 600 durch menschliches Serum angegeben.

Kinetische Grundlagen, Michaelis-Konstanten, pH-Optimum und Normalwertè werden beschrieben.

A simple, continuous, photometric test is described for the measurement of the enzymic hydrolysis of $\mathrm{E} 600$ by human serum. The kinetic basis of the test, Michaelis constants, the $\mathrm{pH}$ optimum and normal values are described.

Beim Zusatz von Serum zu einer wäßr. E 600-Lösung tritt eine rasch zunehmende Gelbfärbung auf. Diese ist auf Freisetzung von p-Nitrophenol durch enzymatische Hydrolyse des E 600 nach folgender Gleichung zurückzuführen:

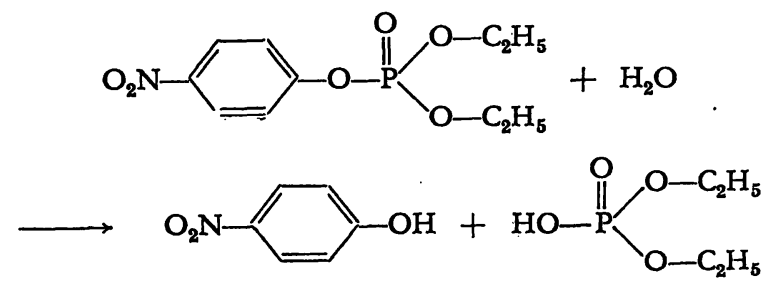

Als Meßgröße dient p-Nitrophenol, das. bei $405 \mathrm{~nm}$ im kontinuierlichen photometrischen Test direkt in der
Küvette gemessen werden kann (s. Methodik). Nach einer Einteilung von AldRIDGE $(1,2)$ bezeichnet man Carboxylesterasen, welche durch organische Phosphorsäureester nicht gehemmt werden, als A-Esterasen ${ }^{1}$ ). Nach AldRIDGe ist die E 600-spaltende Aktivität des Serums mit der aromatische Ester (wie z. B. p-Nitrophenylacetat) hydrolysierenden sog. A-Esterase identisch. Sie läßt sich jedoch von der Procain-, Atropin- und Pseudocholinesterase abgrenzen (2). Das Vorkommen von A-Esterasen im Serum verschiedener Tierarten ist

1) Der Trivialname A-Esterase wird hier gebraucht für das Enzym Arylester-Hydrolase, EC 3.1.1.2.; B-Esterase für Carboxylesterase EC 3.1.1.1; Procain-, Atropin- und Pseudocholinesterase für Cholinesterase EC 3.1.1.8. 
bekannt (1-5). Es fehlt jedoch an Untersuchungen zur näheren Charakterisierung dieser Enzymaktivität im menschlichen Serum. Es ist darüber hinaus von Interesse, ob die A-Esterase des Serums unter pathologischen Bedingungen Veränderungen zeigt.

In der vorliegenden Arbeit wird über die enzymatische Hydrolyse von E 600 durch menschliches Serum, insbesondere über die enzymkinetischen Grundlagen und Normalwerte, berichtet.

\section{Methodik}

Standard-Test

Lösungen

$0,1 \mathrm{M}$ Glycin-Natronlauge-Puffer (6) $\mathrm{pH} 11,2$.

E 600 -Stammlösung (7); $1,2 \cdot 10^{-2_{M}} \mathrm{E} 600$ in $0,1 \mathrm{M}$. Trispuffer $\mathrm{pH}$ 8,0. Diese Stammlösung wird zum Gebrauch jeweils 1:5 mit dest. Wasser verdünnt.

Serum, 1:5 mit 0,9proz. Kochsalzlösung verdünnt.

Ansatz

In eine Küvettc (Schichtdicke $1 \mathrm{~cm}$ ) werden pipettiert: $1,65 \mathrm{~m} /$ Puffer

$+0,25 \mathrm{ml} 1: 5$ verd. Serum

$+0,50 \mathrm{ml}$ E 600-Lösung.

Messung

Nach Durchmischen mit einem unten abgeflachten Glasstab wird in Abständen von 30 Sek. die Extinktion bei $405 \mathrm{~nm}$ im Photometer "Eppendorf" abgelesen. $t=25^{\circ}$. Ausgewertet wird die Extinktionsdifferenz 180 minus 30 Sek. Vom Vollwert wird der unte1 gleichen Bedingungen gemessene E 600-Leerwert (ohne Serum) abgezogen.

\section{Berecbnung}

Zur Umrechnung der Extinktionsdifferenzen in nMol wird der molare Extinktionskoeffizient von p-Nitrophenol (in Glycin$\mathrm{NaOH}$-Puffer $\mathrm{pH} 11,2) \varepsilon_{405} \mathrm{~nm}=18,05 \cdot 10^{6} \mathrm{~cm}^{2} \cdot \mathrm{Mol}^{-1} \mathrm{zu}$ grunde gelegt. $10 \mathrm{nMol}$ p-Nitrophenol gelöst in $1 \mathrm{~m} /$ hätten danach (bei $\mathrm{d}=1 \mathrm{~cm}$ und $\lambda=405 \mathrm{~nm}$ ) eine Extinktion von 0,1805 . Unter weiterer Berücksichtigung der Serumverdünnung (Umrechnung auf $\mathrm{m} l$ Serum durch Multiplikation mit 20), der Meßzeit (Umrechnung auf $1 \mathrm{Min}$. durch Division durch 2,5) und des Ansatzvolumens $(2,4 \mathrm{ml}$; Multiplikation mit 2,4) errechnet sich die Aktivität (in $\mu \mathrm{Mol} \cdot \mathrm{Min}^{-1} \cdot l^{-1}$ Serum) nach folgender Formel:

$$
\text { Aktivität }=\frac{\Delta_{\mathrm{E}} \cdot 10 \cdot 2,4 \cdot 20}{0,1805 \cdot 2,5}=\Delta_{\mathrm{E}} \cdot 1063(\mathrm{U} / / \text { Serum })
$$

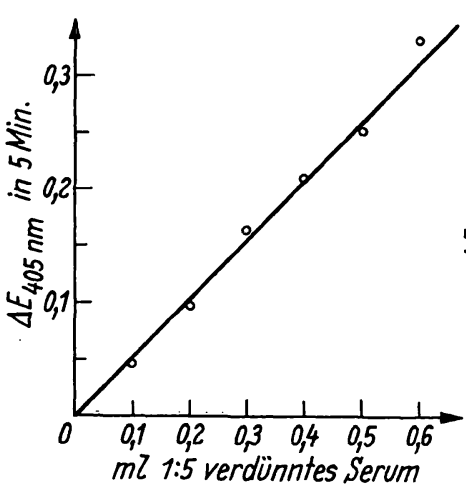

Abb. 1

Einfluß der Serumkonzentration auf die enzymatische Hydrolyse von $\mathrm{E} 600$

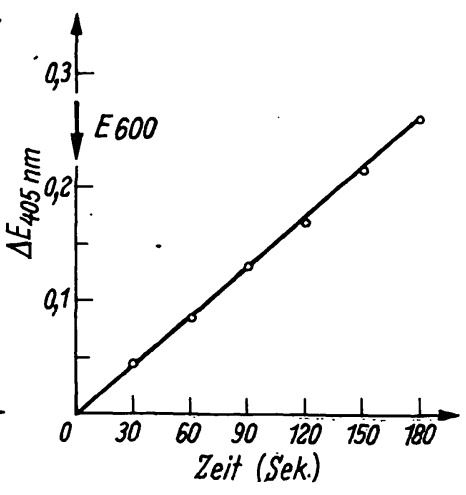

Abb.'2

Optischer Test zur Bestimmung der E 600-Spaltung durch Serum. Zeit-UmsatzKurve

\section{Ergebnisse}

Abhängigkeit der Reaktionsgeschwindigkeit

a) von der Serumkonzentration

Wir haben zunächst die Freisetzung von p-Nitrophenol aus $\mathrm{E} 600$ in Abhängigkeit von der eingesetzten Serummenge verfolgt. Die erhaltenen Werte sind in Abbildung 1 dargestellt. Die Reaktionsgeschwindigkeit ist im angegebenen Bereich eine lineare Funktion der Serumkonzentration. Zur Prüfung des enzymatischen Charakters der Reaktion wurde Serum (1:5 mit 0,9proz. Kochsalzlösung verdünnt) 5 Min. auf $68^{\circ}$ erhitzt. Danach war keine Aktivität mehr meßbar. Auch enteiweißtes Serumfiltrat und eingeengte Außenflüssigkeit nach Dialyse des Serums waren inaktiv.

\section{b) von der Zeit}

Der von uns ausgearbeitete Standardtest (s. Methodik) ermöglicht eine einfache kontinuierliche Bestimmung der E 600-spaltenden Aktivität direkt in der Küvette. Nach der in Abbildung 2 gezeigten Zeit-Umsatz-Kurve verläuft die Reaktion mindestens $3 \mathrm{Min}$. lang linear. Es werden also unter den angegebenen Bedingungen Anfangsgeschwindigkeiten gemessen. Die Enzymaktivität ist relativ stabil. Wie Kontrollversuche zeigten, führt Aufbewahrung des Serums bei $20-25^{\circ}$ innerhalb von 7 Stdn. zu keiner nennenswerten Aktivitätsabnahme. Dagegen wurden nach Dialyse des Serums zunehmende Aktivitätsverluste beobachtet.

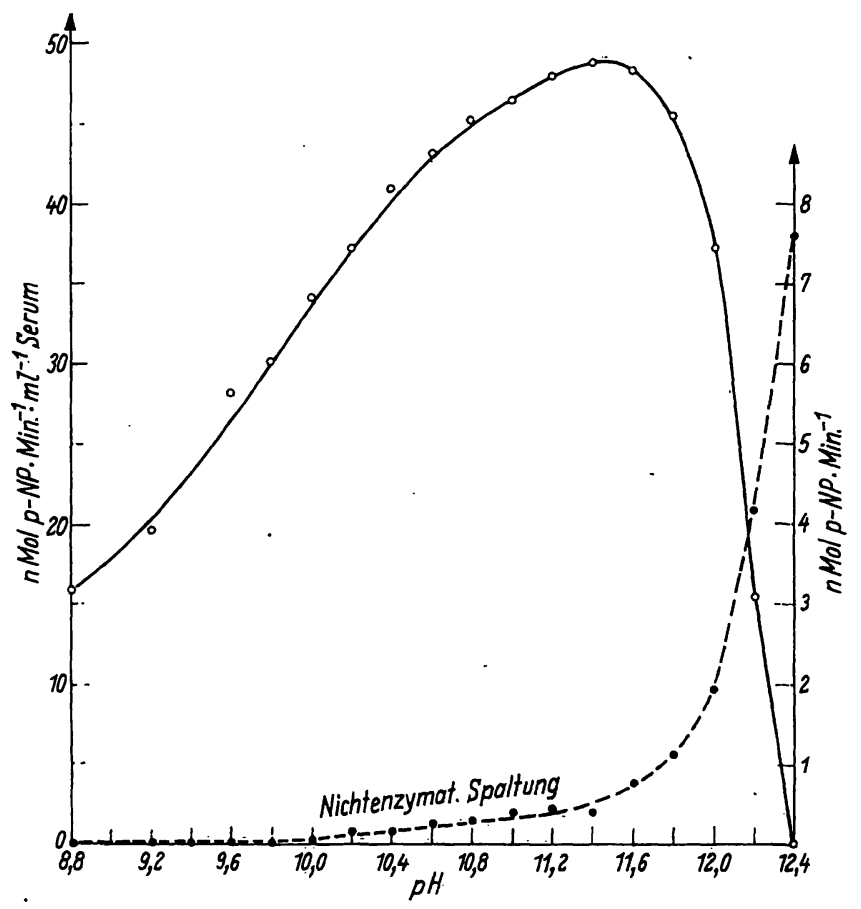

Abb. 3

pH-Optimum der enzymatischen Hydrolyse von E 600. $\longrightarrow$ Ansatz mit Serum tenzymatischer Kontrollansatz (ohne Serum) $\mathrm{p}-\mathrm{NP}=\mathrm{p}-\mathrm{Nitrophenol}$

c) vom $p H$

Abbildung 3 zeigt die pH-Abhängigkeit der enzymatischen Hydrolyse von E 600 durch Humanserum in 0,1M Glycin-Natronlauge-Puffer. Das Optimum liegt im 
stark alkalischen Bereich zwischen pH 11,0 und 11,6. Alle in der vorliegenden Arbeit beschriebenen Teste wurden im genannten Puffer bei $\mathrm{pH} 11,2$ durchgeführt. Vorversuche mit Tris- und Boratpuffer hatten ergeben, daß der Pufferbereich dieser beiden Puffer nach der alkalischen Seite zur Bestimmung des pH-Optimums nicht mehr ausreicht. Die nichtenzymatische Hydrolyse des E 600 steigt, wie ebenfalls aus Abbildung 3 hervorgeht, erst ab pH 12 steil an. Substratleerwerte bei pH 11,2 ohne Serum ergaben im Vergleich zu den Vollwerten mit Serum nur niedrige Extinktionsdifferenzen $\left(\Delta_{E}\right.$ in 150 Sek. 0,003-0,020), die rechnerisch bei der Ermittlung der Aktivitäten mitberücksichtigt wurden.

\section{d) von der Substratkonzentration}

Es wurden bei gleichbleibender Serumkonzentration die Aktivitäten in Gegenwart steigender Konzentrationen an E 600 gemessen. Die erhaltenen Werte wurden doppelt reziprok nach LINEWEAVER-BURK aufgetragen (Abb. 4). Aus dem geradlinigen Verlauf folgt, daß die Spaltung von E 600 durch Serum einer typischen Michaelis-Menten-Kinetik folgt. Die für 7 Normalpersonen ermittelten Michaelis-Konstanten lagen zwischen 2,5 und $5,7 \cdot 10^{-4} \mathrm{M}$.

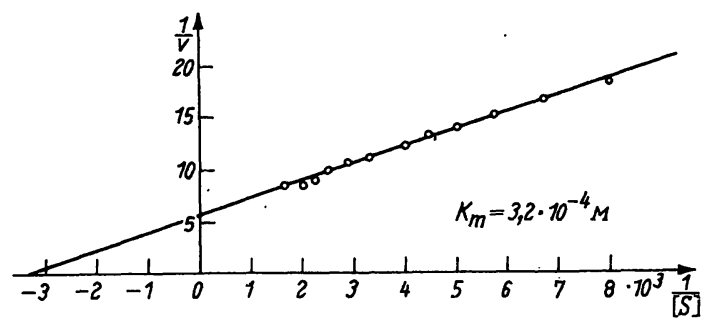

Abb. 4

Hydrolyse von E 600 in Abhängigkeit von der Substratkonzentration. Graphische Ermittlung der $\mathrm{K}_{\mathrm{m}}$ nach LiNewEAVER-BuRK

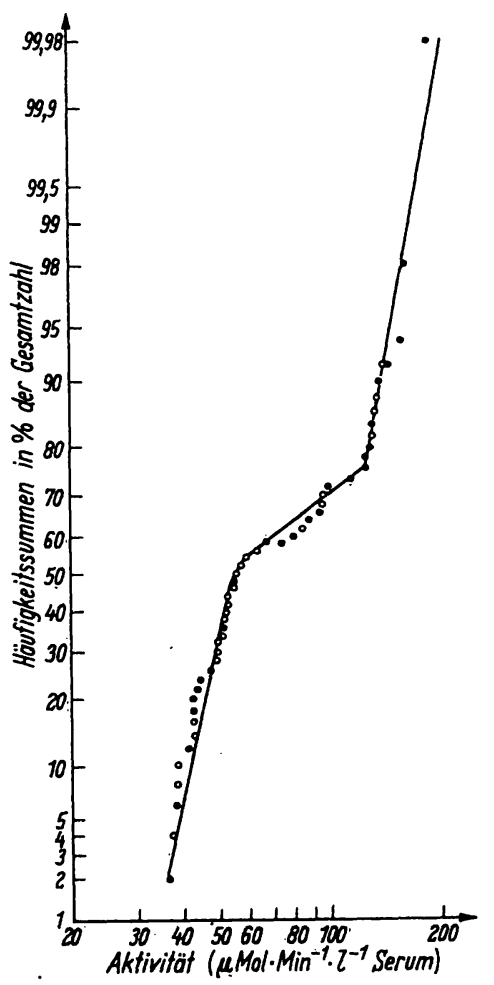

Abb. 5

Normalwerte der E 600spaltenden Aktivität im Serum von je 25 Männern und Frauen. Darstellung im Wahrscheinlichkeitsnetz (Abszisse logarithmisch, Ordinate nach dem Gaưssșchen Integral getẹilt)

- Männer - Frauen

\section{Normalwerte}

Wir haben zunächst die Präzision des in der Methodik angegebenen Testes bestimmt. Bei einer 10fach-Bestimmung des gleichen Serums wurde ein Mittelwert von $63,7 \pm 1,34$ (Standardabweichung) $\mu \mathrm{Mol} \cdot \mathrm{Min}^{-1} \cdot l^{-1}$ gefunden. Der Variationskoeffizient errechnet sich daraus zu 2,1\%. Der methodische Fehler ist im Vergleich zur individuellen biologischen Streuung der Aktivitäten nur gering.

Es wurden dann die Normalwerte von je 25 gesunden Männern und Frauen bestimmt. Die Werte wurden zur Ermittlung des Verteilungstyps in einem Wahrscheinlichkeitsnetz (Abszisse logarithmisch, Ordinate nach dem Gaussschen Integral geteilt) aufgetragen. Dabei ergaben sich zwei Geraden (Abb. 5). Der angegebene Kurvenverlauf ist typisch für eine doppelgipflige logarithmisch-normale Verteilung (8). Die erhaltenen Daten wurden mit Hilfe eines Digitalrechners (IBM 7094) ausgewertet (Verfahren der konjugierten Gradienten) und Mittelwerte, Streuung und Verhältnis der beiden Kollektive bei Männern und Frauen betechnet. Dabei ergab sich bei Männern ein Mittelwert von 55,1 $\pm 3,9$ (Gruppe I) bzw. von $129,8 \pm 6,0 \mu \mathrm{Mol} \cdot \mathrm{Min}^{-1} \cdot \mathrm{l}^{-1}$ (Gruppe II). Die entsprechenden Werte von Frauen betrugen $50,5 \pm 5,1$ und $139,9 \pm 24,0 \mu \mathrm{Mol} \cdot \mathrm{Min}^{-1} \cdot l^{-1}$. Die prozentuale Verteilung auf die beiden Gruppen war bei Männern und Frauen fast gleich (Männer: $78,9 \%$ in Gruppe I, Frauen $79,0 \%$ in Gruppe I und $21,1 \%$ bzw. $21,0 \%$ in Gruppe II).

Reproduzierbarkeit der individuellen Aktivitäten über die Zeit

Angesichts der doppelgipfligen Verteilung der Normalwerte war zu prüfen, inwieweit die Enzymaktivitäten einer Versuchsperson Schwankungen von Tag und Tag unterliegen. Zwei gesunden Personen, von denen eine eine relativ niedrige, die andere eine besonders hohe Aktivität hatte, wurde zweimal wöchentlich Blut abgenommen und die E 600-spaltende Aktivität des Serums unter Standardbedingungen bestimmt. Das Ergebnis ist in Abbildung 6 dargestellt. Man erkennt, daß die jeweilige Aktivität bei der gleichen Versuchsperson nur innerhalb relativ enger Grenzen schwankt. Die mitgeteilten Normalwerte sind also keine zufälligen, z. B. methodisch bedingten, Schwankungen, sondern individuell fixierte und gut reproduzierbare Größen.

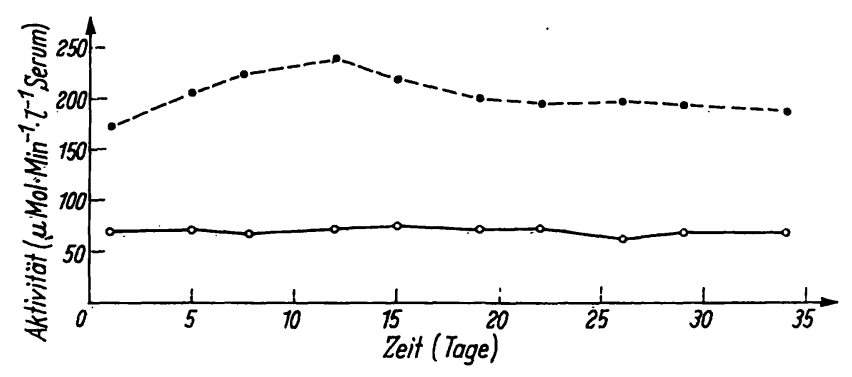

Abb. 6

Wiederholte Bestimmungen der Aktivität bei der gleichen Versuchsperson. ○. K. on, ....... W. S. o 
Tab. 1

Einfluß einiger Inhibitoren auf die enzymatische Spaltung von E 600 durch Serum (Mittelwerte aus je 5 Versuchen)

\begin{tabular}{|c|c|c|c|}
\hline Inhibitor & $\begin{array}{l}\text { Endkonzen- } \\
\text { tration }(M)\end{array}$ & $\begin{array}{c}\text { Aktivität } \\
(\%)\end{array}$ & $\pm s$ \\
\hline
\end{tabular}

Diisopropylfluorophosphat

Physostigmin

Chinin- $\mathrm{HCl}$

Atoxyl

Natriumfluorid

p-Chloromercuribenzoat

Bathocupreindisulfonsäure $\left(\mathrm{Na}_{2}\right)$

o-Phenanthrolin

8-Hydroxychinolin

EDTA

$\begin{array}{rrr}10^{-4} & 85 & 6,1 \\ 10^{-5} & 92 & 2,9 \\ 10^{-3} & 92 & 3,7 \\ 10^{-4} & 93 & 3,3 \\ 10^{-3} & 51 & 10,9 \\ 10^{-4} & 96 & 3,4 \\ 10^{-3} & 95 & 3,6 \\ 10^{-4} & 100 & 1,0 \\ 10^{-3} & 102 & 10,3 \\ 10^{-4} & 97 & 6,7 \\ 10^{-4} & 59 & 24,9 \\ 10^{-8} & 90 & 3,4 \\ 10^{-3} & 60 & 14,9 \\ 10^{-4} & 78 & 9,4 \\ 10^{-3} & 88 & 4,1 \\ 10^{-4} & 94 & 3,6 \\ 10^{-3} & 62 & 9,4 \\ 10^{-4} & 68 & 10,4 \\ 10^{-3} & 45 & 13,6 \\ 10^{-4} & 53 & 15,6\end{array}$

\section{Einflu $\beta$ von Inhibitoren}

Tabelle 1 gibt einen Überblick über den Einfluß einer Reihe von Inhibitoren auf die E 600-Spaltung durch menschliches Serum. Man erkennt, daß das Enzym durch eine Reihe typischer „B-Esterase"-Inhibitoren nicht gehemmt wird. Es scheint dagegen empfindlich gegen einige Chelatbildner zu sein, insbesondere gegen EDTA. Diese, wenn auch nicht sehr ausgeprägte, Hemmbarkeit durch EDTA ließ an eine $\mathrm{Ca}^{++}$-Abhängigkeit der Serumesterase denken. Wie Abbildung 7 zeigt, kann die Aktivität durch Zusatz von $\mathrm{Ca}^{++}$um etwa $40 \%$ gesteigert werden. Dabei liegt die Sättigungskonzentration an $\mathrm{Ca}^{++}$bei etwa $0,5-2 \mu \mathrm{Val}$ $\mathrm{Ca}^{++} / 2,4 \mathrm{~m} l$. (Die Ca-Konzentration des Ansatzes aus dem „endogenen“ $\mathrm{Ca}$ des eingesetzten Serums beträgt demgegenüber etwa $0,5 \mu \mathrm{Val} /$ Ansatz.)

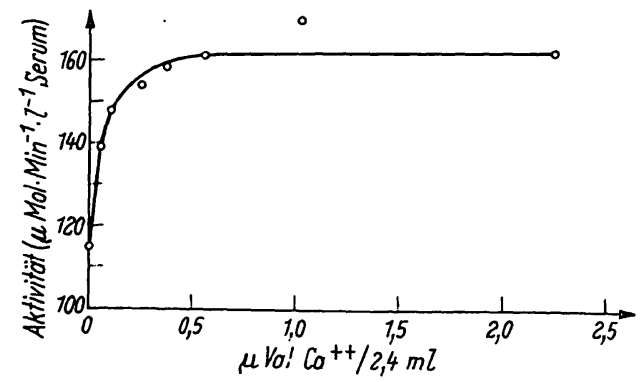

Abb. 7

Abhängigkeit der Aktivität von der Calciumkonzentration

E 600-spaltende Aktivität des Serums bei verschiedenen Erkrankungen

Es war die Frage zu klären, ob die hier näher charakterisierte E 600-spaltende A-Esterase des Serums unter pathologischen Bedingungen signifikante $A b w e i c h u n g e n$ vom angegebenen Normalbereich zeigt und daher von Interesse für die klinische Diagnostik ist. Wir haben die Aktivität bei einer größeren Anzahl von vorwiegend internistischen Erkrankungen (z. B. Diabetes, Leukämie, Plasmocytom, Anämien, Herzinfarkt, Urämie, Polyarthritis, Pankreatitis, Lungen-Tbc., Carcinome, Pso- riasis u. a.) untersucht. In keinem Fall fanden sich statistisch zu sichernde Veränderungen. Auch die bei Hepatitis, Lebercirrhose oder Verschlußikterus gefundenen Werte lagen im Normalbereich.

\section{Diskussion}

Die in der vorliegenden Arbeit untersuchte enzymatische Aktivität von menschlichem Serum gegen E 600 bedarf noch in verschiedener Hinsicht einer näheren Charakterisierung. Dabei wäre von Interesse, welcher Proteinfraktion des Serums diese „A-Esterase" zuzuordnen ist und ob sich Anhaltspunkte für Isoenzyme ergeben. Auch eine Isolierung dieses Enzyms aus menschlichem Serum steht noch aus. Über die Reinigung eines E 600spaltenden Enzyms aus Schafserum wurde von MaiN $(4,5)$ berichtet. Die Aktivität konnte 330-385fach angereichert werden. Nach elektrophoretischen Untersuchungen war die erhaltene Präparation 85-90\% rein. Die Michaelis-Konstante des isolierten Enzyms gegen E 600 war $15 \mathrm{mal}$ größer als die mit Schafserum gefundene $\mathrm{K}_{\mathrm{m}}$. Letztere wird von MarN mit $2,9 \cdot 10^{-4} \mathrm{M}$ angegeben. Dieser Wert stimmt mit dem von uns für menschliches Serum gefundenen gut überein. Auch die von ALDRIDGE (2) für Kaninchenserum angegebene $K_{m}$ $\left(4,5 \cdot 10^{-4} \mathrm{M}\right)$ liegt im gleichen Bereich. Das Molekulargewicht des Enzyms aus Schafserum wird auf 35000 bis 50000 geschätzt. Seine Aktivität wird durch EDTA $\left(10^{-3} \mathrm{M}\right)$ um $93 \%$ gehemmt (4).

Das von uns gefundene pH-Optimum der E 600Spaltung liegt im stark alkalischen Bereich zwischen pH 11,0 und 11,6. Die nicht-enzymatische Hydrolyse spielt jedoch, überraschenderweise, in diesem Bereich noch keine wesentliche Rolle (Abb. 3). Im Gegensatz zu unseren Befunden beim Menschen liegt das pH-Optimum der Hydrolyse von E 600 durch Kaninchenserum zwischen $\mathrm{pH} 7,4$ und 7,6 (2).

Durch das Verhalten gegen Inhibitoren und die Aktivierbarkeit durch $\mathrm{Ca}^{++}$unterscheidet sich die AEsterase des Serums grundlegend von den in unserem Laboratorium aus Leber und Niere vom Schwein bzw. Rind isolierten Carboxylesterasen (EC 3.1.1.1.). Diese werden durch Organophosphat-Inhibitoren rasch und stöchiometrisch gehemmt, ferner durch Chinin, Atoxyl, Natriumfluorid und Physostigmin. Eine $\mathrm{Ca}^{++}-\mathrm{Ab}-$ hängigkeit ließ sich nicht nachweisen $(9,10,11,12)$.

Die übliche Einteilung von Carboxylesterasen in „Ali-“ und „Arylesterasen“ ist aufgrund früherer Befunde von uns fraglich geworden. So hydrolysiert hochgereinigte Carboxylesterase aus Schweineleber nicht nur aliphatische Ester, wie z. B. Tributyrin oder Methylbutyrat, sondern auch aromatische Substrate, wie o- und p-Nitrophenylacetat, $\beta$-Naphtylacetat, Acetanilid, Phenacetin u. a. $(9,10)$. Aber auch die Unterscheidung in A- und BEsterasen, - je nachdem, ob organische Phosphorsäureester als Substrate gespalten werden oder aber als Inhibitoren wirken, - ist nicht.immer stichhaltig. So haben wir kürzlich gezeigt, daß die Phosphorylierung von hochgereinigter Leberesterase durch E 600 reversibel ist; das durch stöchiometrische Mengen E 600 
gehemmte Enzym kann durch sekundäre Hydrolyse des inaktiven phosphorylierten Enzymderivates wieder reaktiviert werden (Halbwertszeit 330 Min. (7)). Man kann daher bei der Reaktion dieses Enzyms mit E 600 zwei Phasen unterscheiden: Eine scbnelle stöchiometrische Initialreaktion, die zu einer schlagartigen Freisetzung („,burst“) von p-Nitrophenol führt, und eine langsame sekundäre Hydrolyse des phosphorylierten Enzymderivates. Nach der Gesamtbilanz wird also E 600 als Substrat auch durch die üblicherweise als „B-Esterase“ angesehene Leberesterase hydrolytisch gespalten, allerdings nur mit sehr geringer Geschwindigkeit. Wie oben mitgeteilt wurde, lassen sich hinsichtlich der E 600spaltenden Aktivität des Serums zwei sich überlagernde Gruppen von Normalpersonen unterscheiden. Dabei handelt es sich um logarithmisch-normale Verteilungen. Der prozentuale Anteil an den beiden Gruppen ist bei Männern und Frauen gleich, jedoch waren der Mittelwert der zweiten Gruppe (hohe Aktivitäten) sowie die Streuung bei den Frauen größer. Es erhebt sich die Frage, ob die Aktivitätsunterschiede der beiden Gruppen durch quantitative Unterschiede des gleichen Enzymproteins oder durch das Vorliegen von zwei qualitativ verschiedenen Enzymproteinen bedingt sind. Ein Kriterium hierfür wäre die Affinität zum Substrat. Es war daher interessant, ob Versuchspersonen mit hohen Aktivitäten andere Michaelis-Konstanten zeigen als Personen mit niedrigen Aktivitäten. Dies war in unseren Versuchen nicht der Fall: alle $K_{m}$-Werte lagen, unabhängig von der Höhe der Aktivitäten, innerhalb der Fehlerbreite im gleichen Bereich $\left(2,5-5,7 \cdot 10^{-4} \mathrm{M}\right)$. Hierbei muß allerdings einschränkend darauf hingewiesen werden, $\mathrm{da} ß$ es im Einzelfall wegen des großen Überlagerungsbereiches nicht sicher möglich ist zu entscheiden, zu welcher der beiden Gruppen eine Versuchsperson gehört.

Möglicherweise sind die Aktivitätsunterschiede zwischen den beiden Gruppen genetisch bedingt. Hierfür gibt es eine Reihe von Beispielen, zu denen die gut untersuchte Pseudocholinesterase des Serums gehört (14). Bei einer kleinen Gruppe von Patienten findet sich eine sehr niedrige Aktivițät dieses Enzyms, die aufgrund des verlangsamten Abbaues von Succinylcholin, einem Muskelrelaxans, zu Narkosezwischenfällen geführt hat. Bei der Pseudocholinesterase liegt die Ursache offenbar in einer qualitativen Verschiedenheit der beiden Enzymproteine, die in verschiedenen Michaelis-Konstanten und einer unterschiedlichen Hemmbarkeit durch Dibucain zum Ausdruck kommt. Es liegt daher nahe, hier eine Mutation des Strukturgenes anzunehmen. - In zahlreichen Untersuchungen zur Bestimmung der E 600spaltenden Aktivität im Serum von Patienten mit verschiedenen, vorwiegend internistischen Erkrankungen, beobachteten wir bisher keine signifikanten Abweichungen vom Normalbereich. Somit haben sich unsere Hoffnungen, daß die methodisch sehr einfach zu bestimmende E 600-Spaltung durch Serum die enzymologische Diagnostik bereichern könnte, bisher nicht erfüllt.

Uber die Organherkunft der sog. „A-Esterase“ im menschlichen Serum ist wenig bekannt. Bei Kaninchen und Ratten liegen hierüber einige Befunde vor (2). Außer im Serum fanden sich die höchsten Aktivitäten in Leber, Lunge, Herz, Nebenniere, Niere, Milz (Kaninchen) bzw. in Leber, Milz, Niere, sowie Herz- und Skelettmuskel (Ratte). Hiernach würde es sich um ein weitverbreitetes, d. h. wenig organspezifisches Enzym handeln.

Der Autor dankt der Deutschen Forschungsgemeinschaft für die Unterstützung unserer Arbeit durch Sachbeibilfen und Frl. W. SEIFERT für geschickte und fleißige Mitarbeit. Herrn Dipl.-Math. Dr. med. R. REPGES, Institut für Biochemie und Endokrinologie der Haustiere (Direktor: Prof. Dr. Dr. Boguth) der Universität Gießen bin ich für die statistische Analyse der Normalwerte zu Dank verpflichtet. Den BAYER-Werken, Leverkusen, Pflanzenschutz-Abteilung, danken wir für die freundliche Überlassung von E 600 (99\% rein).

\section{Literatur}

1. Aldridge, W. N., Biochem. J. 53, 110 (1953). -2. Aldridge, W. N., Biochem. J. 53, 117 (1953). - 3. Aldridge, W. N., Biochem. J. 57, 692 (1954). - 4. MAYN, A. R., Biochem. J. 74, 10 (1960). - 5. MarN, A. R., Biochem. J. 75, 188 (1960). - 6. SörenSEN, S. P. L., Biochem. Z. 21, 131 (1909). - 7. KRrSCH, K., Biochim. biophyșica Acța (Amsterdam) 122, 265 (1966). - 8. Doerffer, K., Beurteilung von Analysenverfahren und -Ergebnissen, S. 24, Springer-Verlag, Berlin-Göttingen-Heidelberg;
J. F. Bergmann, München (1962). - 9. KRIsch, K., Biochem. Z. 337, 531, 546 (1963). - 10. Bernhammer, E. und K. Krisch, Biochem. Pharmacol. 14, 863 (1965). - 11. Franz, W. und K. KRISCH, Biochem. biophys. Res. Commun. 23, 816 (1966). - 12. BeNöHR, H. C. und K. KRISCH, Hoppe-Seyler's Z. physiol. Chem. 348, 1102, 1115 (1967). - 13. Kalow, W., Pharmacogenetics, S. 69; W. B. Saunders Comp., Philadelphia-London (1962).

Professor Dr. K. Krisch 63 Gießen, Friedrichstr. 24 